\title{
Effect of Mg-Zn-Nd Quasicrystal Addition on Corrosion Resistance of AZ91 Alloys
}

\author{
Zhao Zhenwei, Teng Xinying, Zhou Guorong, Leng Jinfeng, Geng Jiwei \\ University of Jinan, Jinan 250022, China
}

\begin{abstract}
The purpose of this study is to improve the corrosion resistance of AZ91 alloys through adding different contents of $\mathrm{Mg}-\mathrm{Zn}-\mathrm{Nd}$ quasicrystal master alloy. The microstructure and the corrosion behavior of AZ91 alloys with addition of $\mathrm{Mg}-\mathrm{Zn}-\mathrm{Nd}$ (MZN) quasicrystal master alloy were investigated by scanning electron microscopy (SEM) equipped with electron dispersive spectroscopy (EDS), X-ray diffractometry (XRD), mass loss tests and potentiodynamic polarization measurements. The results show that the microstructures of AZ91 alloys are significantly refined, and the morphology of $\beta-\mathrm{Mg}_{17} \mathrm{Al}_{12}$ phase changes from a continuous net to a discrete net or even to particles after adding MZN quasicrystal master alloy. Moreover, the amount of $\beta$ - $\mathrm{Mg}_{17} \mathrm{Al}_{12}$ phase is reduced. The alloy with $6 \mathrm{wt} \% \mathrm{MZN}$ quasicrystal master alloy has the best corrosion resistance, and the corrosion rate is 0.8 $\left(\mathrm{mg} \cdot \mathrm{cm}^{-2}\right) / \mathrm{d}$, only $1 / 15$ of that of common AZ91 alloy, but the excessive MZN quasicrystal master alloy could result in a poorer corrosion resistance of AZ91 alloy.
\end{abstract}

Key words: magnesium alloy; mass loss; quasicrystal; corrosion resistance

Magnesium alloys have attracted a great deal of attention as structural materials due to their advanced properties such as low density, high specific-strength, high specific-stiffness, good casting-ability, good dimensional stability, good damping capacity and wonderful electromagnetic shielding characteristic $^{[1-3]}$. These properties make magnesium alloys very attractive for applications in automotive and aerospace industries. However, their applications are still limited due to the relatively poor corrosion resistance ${ }^{[4,5]}$. Therefore, it is necessary to study how to enhance the corrosion resistance of magnesium alloys. AZ91 alloy is a category of widely used magnesium alloys because of its good general properties. Many reports suggest that its corrosion behavior is significantly dependent on its microstructure ${ }^{[6-9]}$.

Magnesium matrix quasicrystals as a new type of magnesium-based materials, have a unique quasi-periodic lattice structure and special properties such as high hardness, high corrosion resistance, low surface energy and good wettability with magnesium matrix ${ }^{[10,11]}$. Magnesium matrix quasicrystal particles can influence significantly the microstructures and refine grains of magnesium alloys. Recent studies suggest that grain refinement can enhance the corrosion resistance of magnesium and its alloys. The purpose of this study is to improve the corrosion resistance of AZ91 alloys through adding different contents of $\mathrm{Mg}-\mathrm{Zn}-\mathrm{Nd}$ quasicrystal master alloy in $3.5 \mathrm{wt} \% \mathrm{NaCl}$ solution. It is hoped that an efficient way can be developed to improve the corrosion resistance of AZ91 alloys, and the significant preliminary results can extend the application field of AZ91 alloys ${ }^{[12-14]}$.

\section{Experiment}

In this study, the chemical compositions of AZ91 alloys are shown in Table 1. All samples used for tests were cut from the mid portion of the alloy ingots individually, the immersion test samples and the electrochemical measurement specimens had a dimension of $10 \mathrm{~mm} \times 10 \mathrm{~mm} \times 6 \mathrm{~mm}$. The samples were weighed before exposure using a digital balance with an accuracy of $0.0001 \mathrm{~g}$ for the original weight. The immersion test was performed in $3.5 \mathrm{wt} \% \mathrm{NaCl}$ solution for different time of 12, 24, 48, 72, 96 and $120 \mathrm{~h}$ at $T=25{ }^{\circ} \mathrm{C}$. The corroded

Received date: March 25, 2013

Foundation item: the Award Fund for Outstanding Young Scientist in Shandong Province (BS2011CL004); PH.D Foundation of University of Jinan (XBS1107)

Corresponging author: Teng Xinying, Ph. D., School of Materials Science and Engineering, University of Jinan, Jinan 250022, P. R. China, Tel: 0086-531-82765317,

E-mail: mse_tengxy@ujn.edu.cn

Copyright () 2014, Northwest Institute for Nonferrous Metal Research. Published by Elsevier BV. All rights reserved. 
Table 1 Chemical composition of magnesium alloys (wt\%)

\begin{tabular}{cccccc}
\hline Alloy No. & $\mathrm{Zn}$ & $\mathrm{Al}$ & $\mathrm{Be}$ & $\mathrm{Mg}$ & $\mathrm{MZN}$ \\
\hline 1 & 1.00 & 9.00 & 0.010 & Bal. & 0 \\
2 & 1.03 & 8.92 & 0.010 & Bal. & 2 \\
3 & 0.96 & 8.97 & 0.010 & Bal. & 4 \\
4 & 0.99 & 8.89 & 0.010 & Bal. & 6 \\
5 & 1.05 & 8.95 & 0.010 & Bal. & 8 \\
6 & 1.00 & 8.99 & 0.010 & Bal. & 10 \\
\hline
\end{tabular}

specimens were washed by a chromate solution $\left(15 \% \mathrm{CrO}_{3}+1 \%\right.$ $\mathrm{AgNO}_{3}$ ) for 3 5 min to remove the corrosion products. Finally, the specimens were washed with alcohol and deionized water, dried by hot air flow and reweighed to obtain the mass loss.

The microstructure and the composition of different phases in the alloys were investigated by scanning electron microscopy (FEI QUANTA FEG250) equipped with electron dispersive spectroscopy (EDS). Phase analysis was determined by X-ray diffractometer (D8-ADVANCE) using monochromatic $\mathrm{Cu} \mathrm{K \alpha}$ radiation. Potentiodynamic polarization experiments were performed in electrochemical workstation (Gaoss Union EC500).

\section{Results and Discussion}

\subsection{Mg-Zn-Nd quasicrystal master alloy}

The X-ray diffraction pattern and the optical micrograph of $\mathrm{Mg}-\mathrm{Zn}-\mathrm{Nd}(\mathrm{MZN})$ quasicrystal master alloy are displayed in Fig.1. According to the X-ray diffraction pattern (Fig.1a), the microstructure of MZN quasicrystal master alloy mainly consists of $\mathrm{Mg}_{7} \mathrm{Zn}_{3}$ phase and spherical quasicrystal phase (I-phase). Fig.1b shows the microstructure of as-cast MZN quasicrystal master alloy, which displays that the spherical I-phases are (marked by arrows in Fig.1b) homogeneously distributed in the matrix. Compared with petal-like quasicrystal in $\mathrm{Mg}-\mathrm{Zn}-\mathrm{Y}$ alloy, spherical quasicrystal particles in $\mathrm{Mg}-\mathrm{Zn}-\mathrm{Nd}$ alloy have smaller average size and larger amount. It is clear that the average diameter of all spherical I-phases with high roundness is below $10 \mu \mathrm{m}$. In the previous study ${ }^{[15-17]}$, the average composition of the spherical I-phase in MZN alloy is $\mathrm{Mg}_{40} \mathrm{Zn}_{55} \mathrm{Nd}_{5}$, which was first reported by Niikura et $\mathrm{al}^{[18]}$.

\subsection{Microstructures of AZ91 alloys with different additions of MZN}

Fig.2 displays the optical micrographs of as-cast AZ91 alloys with different contents of MZN quasicrystal master alloys. The microstructure of as-cast AZ91 alloy mainly consists of the $\alpha$-Mg matrix phase and the $\beta$ - $\mathrm{Mg}_{17} \mathrm{Al}_{12}$ phase (shown in Fig.2a). With increasing of addition level of MZN quasicrystal master alloy, the grain size of the matrix microstructure decreases continuously and the morphology of $\beta-\mathrm{Mg}_{17} \mathrm{Al}_{12}$ phase changes from continuous nets to discrete nets or even to particles. Moreover, the amount of $\beta-\mathrm{Mg}_{17} \mathrm{Al}_{12}$ phase is reduced. When the addition level reaches $6 \%$, the microstructure of the alloy is obviously refined. It is an optimal addition for MZN quasicrystal master alloy to refine matrix microstructure of

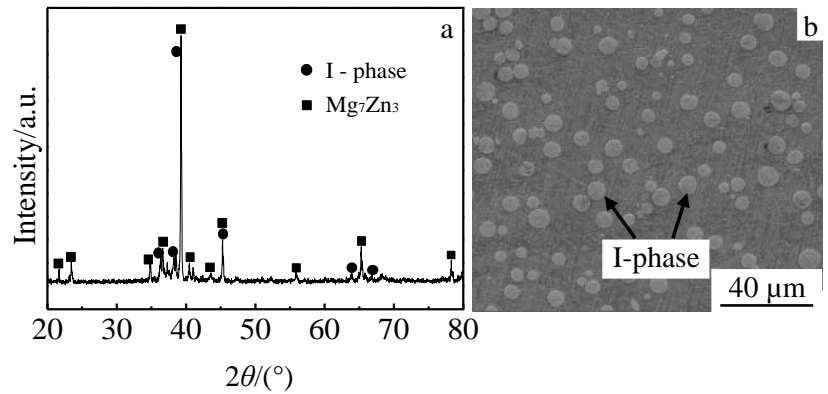

Fig.1 X-ray diffraction pattern (a) and optical micrograph (b) of MZN quasicrystal master alloy

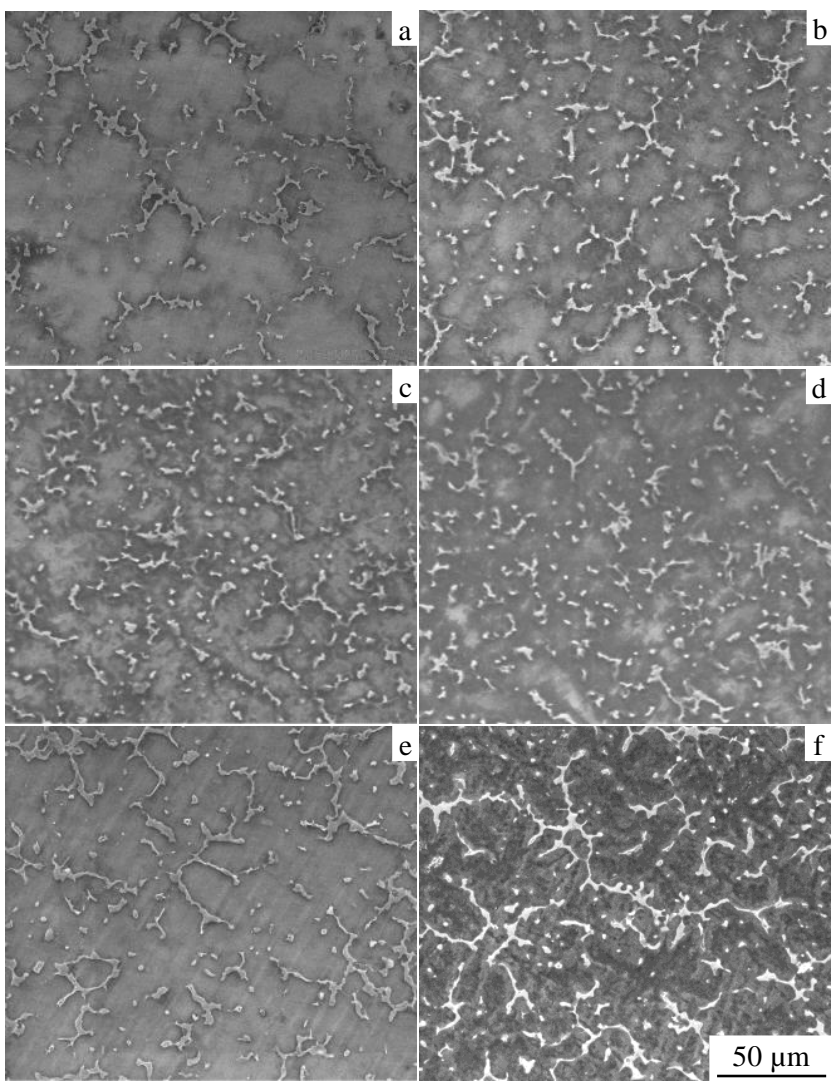

Fig.2 Microstructures of as-cast AZ91 alloys with different additions of MZN quasicrystal master alloys: (a) AZ91, (b) AZ91+2\% MZN, (c) AZ91+4\% MZN, (d) AZ91+6\% MZN, (e) AZ91+8\% MZN, and (f) AZ91+10\% MZN

AZ91 alloys. With the addition level surpassing 6\%, the grain size of the matrix microstructure begins to coarsen. The stable quasicrystal phases are homogeneously distributed in the matrix and on the grain boundaries, which has great contribution to the grain refinement of the matrix of AZ91 alloys. I-phase particles congregate at the front of growing interface and block the diffusion of $\mathrm{Al}$ and $\mathrm{Zn}$ atoms during the solidification process, which suppresses the growth of $\alpha-\mathrm{Mg}$ and $\beta-\mathrm{Mg}_{17} \mathrm{Al}_{12}{ }^{[19]}$, and finally the matrix microstructure of AZ91 alloys is refined.

A small amount of fine white particles are also observed at 
the grain boundaries as well as in the matrix. The further magnified SEM image and the EDS analysis of the fine particle are shown clearly in Fig.3. From Fig.3a, there are white particle-like quasicrystal phases distributed on the grain boundary and in the matrix. The EDS analysis is used to verify the micro-composition of the alloy. The EDS analysis confirms that the white granular compound (marked by arrows in Fig.3a) is spherical I-phase. Fig.3c displays the X-ray diffraction patterns. The microstructure of AZ91 mother alloy consists of $\alpha-\mathrm{Mg}$ matrix phase and $\beta-\mathrm{Mg}_{17} \mathrm{Al}_{12}$ phase. However, after adding $6 \%$ MZN quasicrystal master alloy, the new diffraction peaks for spherical quasicrystal phase appear, which indicates that the microstructure of AZ91 with adding MZN quasicrystal master alloy consists of $\alpha-\mathrm{Mg}$ matrix phase, $\beta-\mathrm{Mg}_{17} \mathrm{Al}_{12}$ phase and spherical I-phase. So the spherical I-phase can be inherited well in AZ91 alloy, which can change the microstructures of AZ91 alloys.

\subsection{Effect of MZN alloy on corrosion resistance of AZ91 alloys}

With respect to the determination of corrosion rates, the most accurate and precise method is probably the mass loss test ${ }^{[20]}$. The average corrosion rates of AZ91 alloys with and without MZN quasicrystal master alloy obtained from the mass loss tests are shown in Fig.4. The corrosion resistance of alloys is improved remarkably due to the MZN quasicrystal addition and accompanied by the increase of MZN quasicrystal the corrosion rate decreases gradually. When the addition of MZN quasicrystal master alloy is up to $6 \%$, the corrosion rate reaches the minimum value of $0.8\left(\mathrm{mg} \cdot \mathrm{cm}^{-2}\right) / \mathrm{d}$, which contrasts brightly

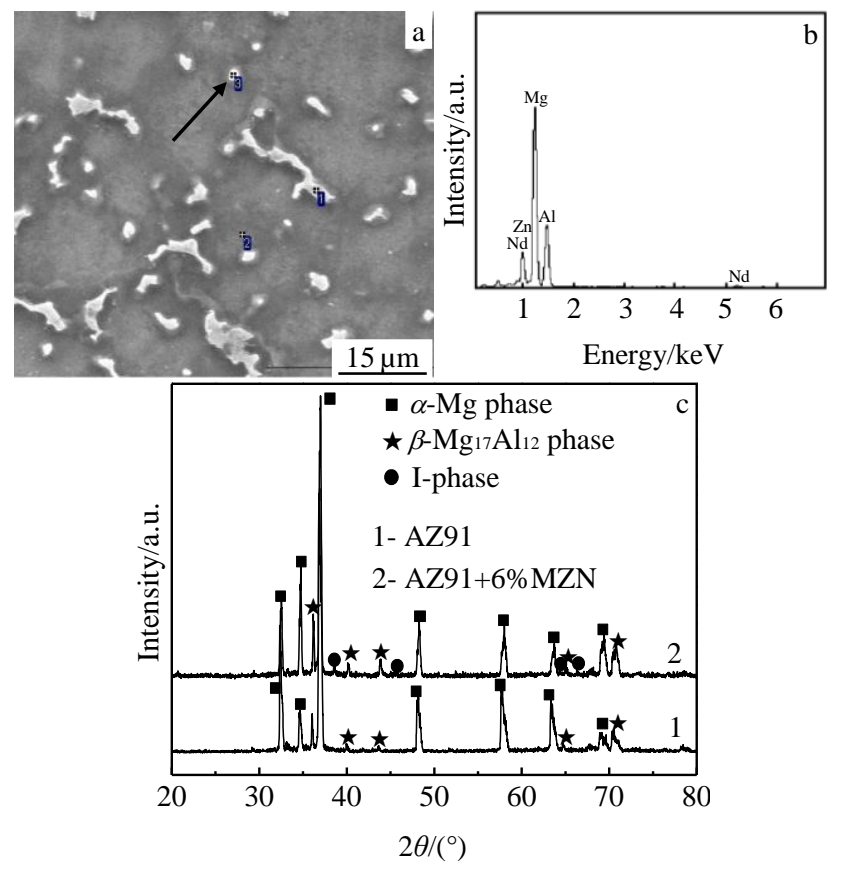

Fig.3 Optical micrograph (a), the EDS spectrum (b) of AZ91+6\% MZN master alloy and X-ray diffraction pattern of the alloys (c)

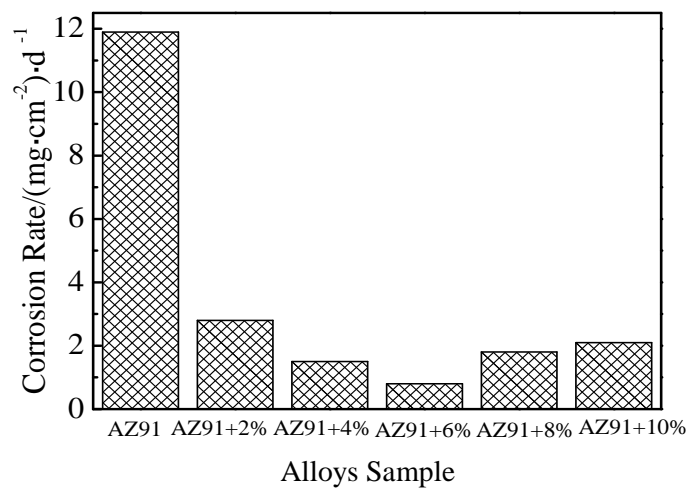

Fig.4 Average corrosion rates of different alloys immersed in 3.5\% $\mathrm{NaCl}$ solution for $5 \mathrm{~d}$ by mass loss tests

with the value of $11.9\left(\mathrm{mg} \cdot \mathrm{cm}^{-2}\right) / \mathrm{d}$ of AZ91 mother alloy, 15 times larger than that. The corrosion rate of alloys begins to increase again when the addition of MZN quasicrystal master alloy surpasses $6 \%$.

The potentiodynamic polarization curves of alloys are illustrated in Fig.5. The polarization curves are fitted and the results are shown in Table 2. As listed in Table 2, after the addition of the MZN quasicrystal master alloy, the corrosion current densities $\left(J_{\text {corr }}\right)$ of the alloys with MZN quasicrystal master alloy are lower than that of AZ91 alloy, which indicates the presence of MZN quasicrystal decreases the corrosion current densities of the alloys. The corrosion current density deduced from polarization measurements could be ranked in the following order: AZ91> $\mathrm{AZ} 91+2 \% \mathrm{MZN}>\mathrm{AZ} 91+10 \% \mathrm{MZN}>\mathrm{AZ} 91+8 \% \mathrm{MZN}>\mathrm{AZ} 91+$ $4 \% \mathrm{MZN}>\mathrm{AZ} 91+6 \% \mathrm{MZN}$. According to Faraday's law, the current density is proportional to the corrosion rate. So the corrosion rate of alloys could be ranked in the following order:

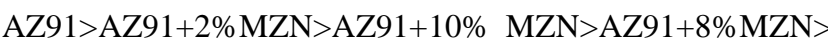
$\mathrm{AZ} 91+4 \% \mathrm{MZN}>\mathrm{AZ} 91+6 \% \mathrm{MZN}$, which indicates that the alloy with $6 \% \mathrm{MZN}$ quasicrystal master alloy has the best corrosion resistance. This result is approximately in accordance with the above mentioned mass loss tests.

The optical micrographs of different alloys after $12 \mathrm{~h}$ immersion are presented in Fig.6. After $12 \mathrm{~h}$ of immersion the specimens of the six alloys present different degrees of corrosion.

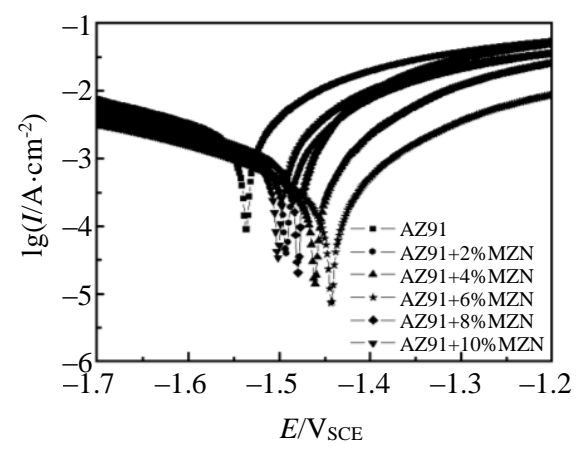

Fig.5 Polarization curves of the alloys immersed in $3.5 \% \mathrm{NaCl}$ solution 
Table 2 Corrosion potentials and corrosion current densities of alloys

\begin{tabular}{ccc}
\hline Sample & $J_{\text {corr }} / \mathrm{mA} \cdot \mathrm{cm}^{-2}$ & $E_{\text {corr }} / V_{\text {SCE }}$ \\
\hline AZ91 & 1.738 & -1.538 \\
AZ91+2\%MZN & 0.648 & -1.492 \\
AZ91+4\%MZN & 0.161 & -1.458 \\
AZ91+6\%MZN & 0.124 & -1.442 \\
AZ91+8\%MZN & 0.216 & -1.478 \\
AZ91+10\%MZN & 0.449 & -1.505 \\
\hline
\end{tabular}

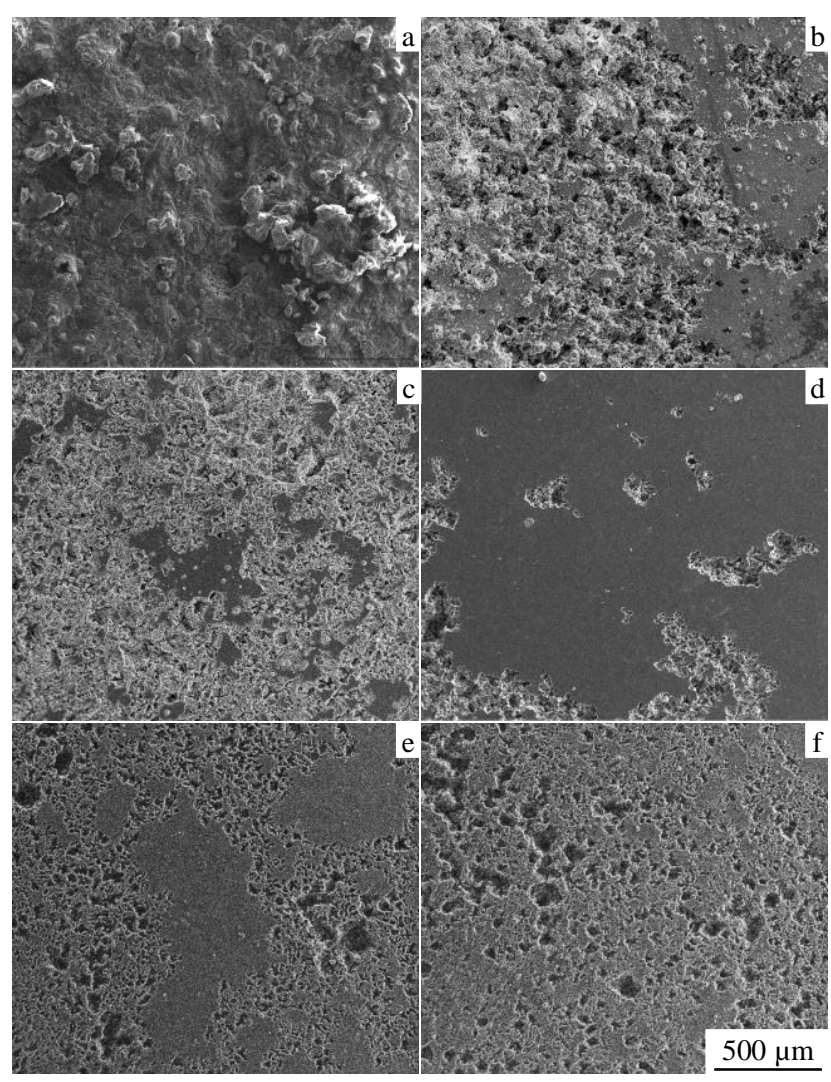

Fig.6 Optical micrographs of different alloys immersed in 3.5\% $\mathrm{NaCl}$ solution for $12 \mathrm{~h}$ : (a) AZ91, (b) AZ91+2\% MZN, (c) $\mathrm{AZ91+4 \%} \mathrm{MZN}$, (d) AZ91+6\% MZN, (e) AZ91+8\% MZN, and (f) AZ91+10\% MZN

The corroded surface area of the AZ91 alloy is larger than those observed on the other five alloys, and the corrosive attack depth of AZ91 alloy is the biggest among all six alloys obviously. In some areas a corrosion develops from the surface to the inside of the alloy, and many deep corrosion pits in the surface of AZ91 alloy can be seen (Fig.6a) clearly when the corrosion products flake off. Compared with AZ91, it is obvious that AZ91+MZN alloys exhibit an excellent corrosion resistance in the same test condition. When the addition of MZN quasicrystal master alloy is up to $6 \%$, the corroded surface area of the alloy is the lightest. However, further addition of MZN over $6 \mathrm{wt} \%$ leads to the bigger corrosive attack, and this indicates that the excessive MZN quasicrystal master alloy can reduce the corrosion resistance of AZ91 alloy, which is in good agreement with the above mentioned corrosion rate measurements. The proper quantity of MZN quasicrystal master alloy can improve the corrosion resistance of AZ91 alloy remarkably.

\subsection{Discussion}

The corrosion of magnesium alloys is closely related to the microstructure changes of magnesium alloys. On the one hand, the grain size of AZ91 alloys is significantly refined after adding MZN quasicrystal master alloy. Aung et al. suggests that the grain boundaries act as a physical corrosion barrier for magnesium alloys ${ }^{[21]}$. Small grain size creates more grain boundaries, and as a consequence, the rate of the corrosion in a small-grained microstructure slowed down compared with coarse-grained microstructure ${ }^{[21]}$. In this work, the alloys of adding MZN quasicrystal master alloy with small grain size illustrate lower corrosion rates compared with the AZ91 alloy, which corresponds well with the suggestions of N. Aung et al. On the other hand, adding MZN quasicrystal master alloy into AZ91 alloy will alter the amount and the distribution of $\beta$ phase. The $\beta$ phase plays an important role in the corrosion resistance of AZ91 alloy ${ }^{[6]}$. As reported, the potential of $\beta-\mathrm{Mg}_{17} \mathrm{Al}_{12}$ phase is $-1.20 \mathrm{~V}_{\mathrm{SCE}}$, more positive than that of $\alpha-\mathrm{Mg}\left(-1.66 \mathrm{~V}_{\mathrm{SCE}}\right)^{[22]}$, so $\alpha$ phase is easier to be corroded than $\beta$ phase. These two phases form a micro-galvanic couple, $\alpha-\mathrm{Mg}$ phase as anode while $\beta-\mathrm{Mg}_{17} \mathrm{Al}_{12}$ phase as cathode. In this study, the addition of MZN quasicrystal master alloy remarkably reduces the amount of $\beta$ phase; consequently this weakens the cathodic role of $\beta$ - $\mathrm{Mg}_{17} \mathrm{Al}_{12}$ phase and efficiently depresses the micro-galvanic couple so as to reduce the corrosion. In addition, the stable quasicrystal phases are homogeneously distributed on the grain boundaries and in the grain interior, which can improve the stability of the matrix, thus reducing the corrosion attack.

However, the excessive quasicrystal phases in AZ91 alloy can improve the amount of $\beta-\mathrm{Mg}_{17} \mathrm{Al}_{12}$ phase on the grain boundaries and cause the grain size of the matrix to coarsen, and consequently the micro-galvanic couples increase. As a result, the micro-galvanic-current density between $\beta$ phase to adjacent $\alpha$ grain rises and decreases the corrosion resistance of AZ91 alloy, which might be the reason why the excessive MZN quasicrystal master alloy could result in lower corrosion resistance of AZ91 alloy.

\section{Conclusions}

1) With adding MZN quasicrystal master alloy into AZ91 alloy, the microstructures of AZ91 alloys are significantly refined, and the morphology of $\beta-\mathrm{Mg}_{17} \mathrm{Al}_{12}$ phase changes from continuous nets to discrete nets or even to particles. When the addition reaches $6 \%$, the finest grain size is obtained. The grain size of the matrix begins to coarsen when the addition surpasses $6 \%$.

2) All the results of the corrosion tests indicate that the presence of MZN quasicrystal master alloys improves the corrosion resistance of alloys. The alloy with $6 \mathrm{wt} \% \mathrm{MZN}$ 
quasicrystal master alloy has the best corrosion resistance. The effect of MZN quasicrystal master alloys on the corrosion behavior of AZ91 alloy can be concluded as three issues. First, the grain boundaries act as a physical corrosion barrier for magnesium alloys. Small grain size creates more grain boundaries, which improves the corrosion resistance of alloys. Second, the addition of MZN quasicrystal master alloy remarkably reduces the size and amount of $\beta$ phase, and consequently efficiently depresses the micro-galvanic couple so as to reduce the corrosion. Moreover, the stable quasicrystal phases are homogeneously distributed on the grain boundaries and in the grain interior, which can improve the stability of the matrix, thus reducing the corrosion attack. However, the excessive MZN quasicrystal master alloy could result in lower corrosion resistance of AZ91 alloy.

\section{References}

1 Luo T J, Yang Y S. Materials and Design[J], 2011, 32: 5043

2 Ballerini G, Bardi U, Bignucolo R et al. Corrosion Science[J], 2005, 47: 2173

3 El-Taib Heakal F, Shehata O S, Tantawy N S et al. International Journal of Hydrogen Energy[J], 2012, 37: 84

4 Guo H X, Ma Y, Wang J S et al. Transactions of Nonferrous Metals Society of China[J], 2012, 22: 1786

5 Arrabal R, Matykina E, Pardo A et al. Corrosion Science[J], 2012, 55: 351

6 Zhang T, Shao Y W, Meng G Z et al. Corrosion Science [J], 2011, 53: 1960

7 Pardo A, Merino M C, Coy A E et al. Electrochimica Acta[J], 2008, 53: 7890
8 Zhao M, Liu M, Song G et al. Corrosion Science[J], 2008, 50: 1939

9 Song Y W, Han E H, Shan D Y et al. Corrosion Science[J], 2012, 60: 238

10 Wan D Q et al. Rare Metal Materials and Engineering[J], 2007, 36(10): 1732 (in Chinese)

11 Cyrot-Lackmann F. Materials Science and Engineering $A[\mathrm{~J}]$, 2000, 294-296: 611

12 Zhang J S, Zhang Y Q, Zhang Y et al. Transactions of Nonferrous Metals Society of China[J], 2010, 20: 1199

13 Arrabal R, Pardo A, Merino M C et al. Corrosion Science[J], 2012, 55: 301

14 Zhang Z, Tremblay R, Dube D. Materials Science and Engineering $A[\mathrm{~J}], 2004,385: 286$

15 Zhang J S, Yan J, Liang W et al. Materials Letters[J], 2008, 62: 4489

16 Zhang J S, Yan J, Liang W et al. Journal of Non-Crystalline Solids[J], 2009, 355: 836

17 Zhang J S, Yan J, Han F Y et al. Journal of Rare Earths[J], 2009, 27: 264 (in Chinese)

18 Niikura A, Tsai A P, Inoue A et al. Japan Journal of Applied Physics[J], 1994, 33: L1538

19 Zhang J S, Pei L X, Du H W et al. Journal of Alloys and Compounds[J], 2008, 453: 309

20 Poorqasemi E, Abootalebi O, Peikari M et al. Corrosion Science [J], 2009, 51: 1043

21 Aung N, Zhou W. Corrosion Science[J], 2010, 52: 589

22 Niu J X, Chen Q R, Xu N X et al. Transactions of Nonferrous Metals Society of China [J], 2008, 18: 1058

\title{
Mg-Zn-Nd 准晶对 AZ91 合金耐腐蚀性能的影响
}

\author{
赵振伟, 滕新营, 周国荣, 冷金凤, 耿继伟 \\ (济南大学, 山东 济南 250022)
}

\begin{abstract}
摘 要: 通过添加不同量的 Mg-Zn-Nd 准晶中间合金提高 AZ91 合金的耐腐蚀性。利用配有能谱分析 (EDS) 的扫描电子显微镜 (SEM), $X$ 射线衍射仪 (XRD), 失重试验和动电位极化测量研究了添加 Mg-Zn-Nd 准晶中间合金的 AZ91 合金微观组织和腐蚀行为。结果表明: 添加 Mg-Zn-Nd 准晶中间合金后, AZ91 合金的显微组织明显细化, $\beta-\mathrm{Mg}_{17} \mathrm{Al}_{12}$ 相由连续的网状分布变成不连续的断网或颗粒状分布。 此外, $\beta-\mathrm{Mg}_{17} \mathrm{Al}_{12}$ 相明显减少。当添加质量分数 $6 \% \mathrm{MZN}$ 准晶中间合金时，合金具有最好的耐腐蚀性，腐蚀速率是 $0.8\left(\mathrm{mg} \cdot \mathrm{cm}^{-2}\right) / \mathrm{d}$, 仅 是 AZ91 合金腐蚀速率的 1/15。但过多的 MZN 准晶中间合金的添加, 会导致 AZ91 合金有较差的耐腐蚀性。
\end{abstract}

关键词：镁合金; 失重法; 准晶; 耐腐蚀

作者简介: 赵振伟, 女, 1986 年生, 硕士生, 济南大学材料科学与工程学院, 山东 济南 250022, 电话: 0531-82765317, E-mail: zhaozhenwei91@163.com 